Review

\title{
Symmetry OUT, Asymmetry IN
}

\section{Raquel Lourenço ${ }^{1,2}$ and Leonor Saúde ${ }^{1,2, *}$}

1 Instituto de Medicina Molecular e Instituto de Histologia e Biologia do Desenvolvimento, Faculdade de Medicina da Universidade de Lisboa, Portugal; E-Mail: ralourenco@fm.ul.pt

2 Instituto Gulbenkian de Ciência, Oeiras, Portugal

* Author to whom correspondence should be addressed; E-Mail: msaude@fm.ul.pt.

Received: 15 March 2010; in revised form: 23 April 2010 / Accepted: 18 May 2010 /

Published: 25 May 2010

\begin{abstract}
The formation of a perfect vertebrate body plan poses many questions that thrill developmental biologists. Special attention has been given to the symmetric segmental patterning that allows the formation of the vertebrae and skeletal muscles. These segmented structures derive from bilaterally symmetric units called somites, which are formed under the control of a segmentation clock. At the same time that these symmetric units are being formed, asymmetric signals are establishing laterality in nearby embryonic tissues, allowing the asymmetric placement of the internal organs. More recently, a "shield" that protects symmetric segmentation from the influence of laterality cues was uncovered. Here we review the mechanisms that control symmetric versus asymmetric development along the left-right axis among vertebrates. We also discuss the impact that these studies might have in the understanding of human congenital disorders characterized by congenital vertebral malformations and abnormal laterality phenotypes.
\end{abstract}

Keywords: segmentation clock; bilateral synchronization; left-right asymmetry; organ laterality

\section{How to Produce a Symmetric Body Plan}

\subsection{The Bilateral Symmetry of Somite Formation}

The bilateral symmetric appearance of the vertebrate body plan is largely due to the symmetric organization of the skeleton and its associated muscles. The origin of this symmetry can be traced back 
to early developmental stages when the somites-embryonic structures that will differentiate into the axial skeleton (vertebrae, intervertebral discs and ribs) and skeletal muscles-are being formed. Each new pair of somites is progressively laid down from the rostral region of the presomitic mesoderm (PSM) in a bilateral symmetric way on both sides of the axial structures i.e., neural tube and notochord. Somite formation is coupled with the constant supply of new somite precursors cells that are added into the caudal region of the PSM coming from a progenitor zone located in the tailbud. The long lasting interest in the somites comes from the observation that these embryonic structures are produced in species-specific regular intervals in space and time. Every 4-5 hours a new pair of somites is formed in the human embryo, every 120 minutes in the mouse, every 90 minutes in the chick and every 30 minutes in the zebrafish [1].

\subsection{The Segmentation Clock Sets the Periodicity of Somite Formation}

The "clock and wavefront" model proposed by Cooke and Zeeman in 1976 provides an explanation for the precise temporal and spatial segmental pattern established in the vertebrate body plan [2]. It postulates the existence of an internal clock that sets the time when PSM cells are competent to form a somite and a wavefront of differentiation that moves posteriorly along the PSM and positions the next pair of somites, i.e., the determination front. With these two components, both temporal and spatial patterns can be established in the PSM. Only when PSM cells are located anterior to the determination front, a transition from an immature to a mature state can occur and a new somite will form in response to the clock cycle.

The molecular evidence for the existence of a segmentation clock came with the discovery of the first cyclic gene, the avian basic-helix-loop-helix (bHLH) transcription factor hairy1. The chick hairy1 gene shows a dynamic and reiterated expression pattern in the PSM with the exact same periodicity of somite formation [3]. These hairy1 mRNA oscillations occur autonomously in PSM cells and because they are synchronized with adjacent cells, describe a wave of expression starting at the posterior PSM and moving towards the anterior PSM, where it slows down and eventually stops, concomitant with somite formation (Figure 1). Therefore, PSM cells undergo several periodic oscillations of hairy1 gene expression before they incorporate into the next somite [3].

Soon after this discovery, several of Hairy-Enhancer of Split-related genes, named hes in mice and her in zebrafish, were identified and shown to produce the same type of oscillating behavior at the level of the PSM [1]. These genes are primary targets of the Notch signaling pathway and encode transcriptional regulators of the bHLH class that mainly work as repressors [4]. This suggested that the oscillatory behavior of the cyclic genes could be due to feedback inhibition. Indeed, the first indication that this was the case came from a pioneering study performed in cell culture. It was shown that not only the mRNA but also the Hes1 protein levels oscillate with the same periodicity as somite formation. These oscillations are generated by a negative feedback mechanism, where the Hes1 protein periodically represses its own transcription [5]. It has been shown that negative feedback loops also underlie the oscillatory expression of a number of cyclic genes in the mouse, zebrafish and chick PSM [6-12]. A mathematical model based essentially on experimental data of zebrafish her genes clearly shows that sustained oscillations can indeed be generated by a negative feedback loop, if transcriptional and translational time delays are taken into account and if the half-life of cyclic 
mRNAs and proteins are short [13]. Data obtained in the mouse is also in agreement with this model, since a disorganized oscillatory gene expression and a perturbation in somite formation are observed when the half-life of Hes 7 protein is increased [10].

Figure 1. The formation of a new pair of somites is under the control of a molecular clock and a wavefront of differentiation. mRNA oscillations of cyclic genes are detected in PSM cells (blue dots) and since they are synchronized with neighboring cells, describe a wave of expression that starts at the posterior region of the PSM and moves towards the anterior region of the PSM. Here, the wave of expression slows down and stabilizes in the formed somite (S-I). Somite formation is also under the control of a wavefront of differentiation defined by an Fgf/Wnt signaling gradient in the posterior region of the PSM, which is counteracted by a RA gradient in the anterior region of the PSM. Anterior (A) is up, posterior is down (P). S-0 is the new forming somite.

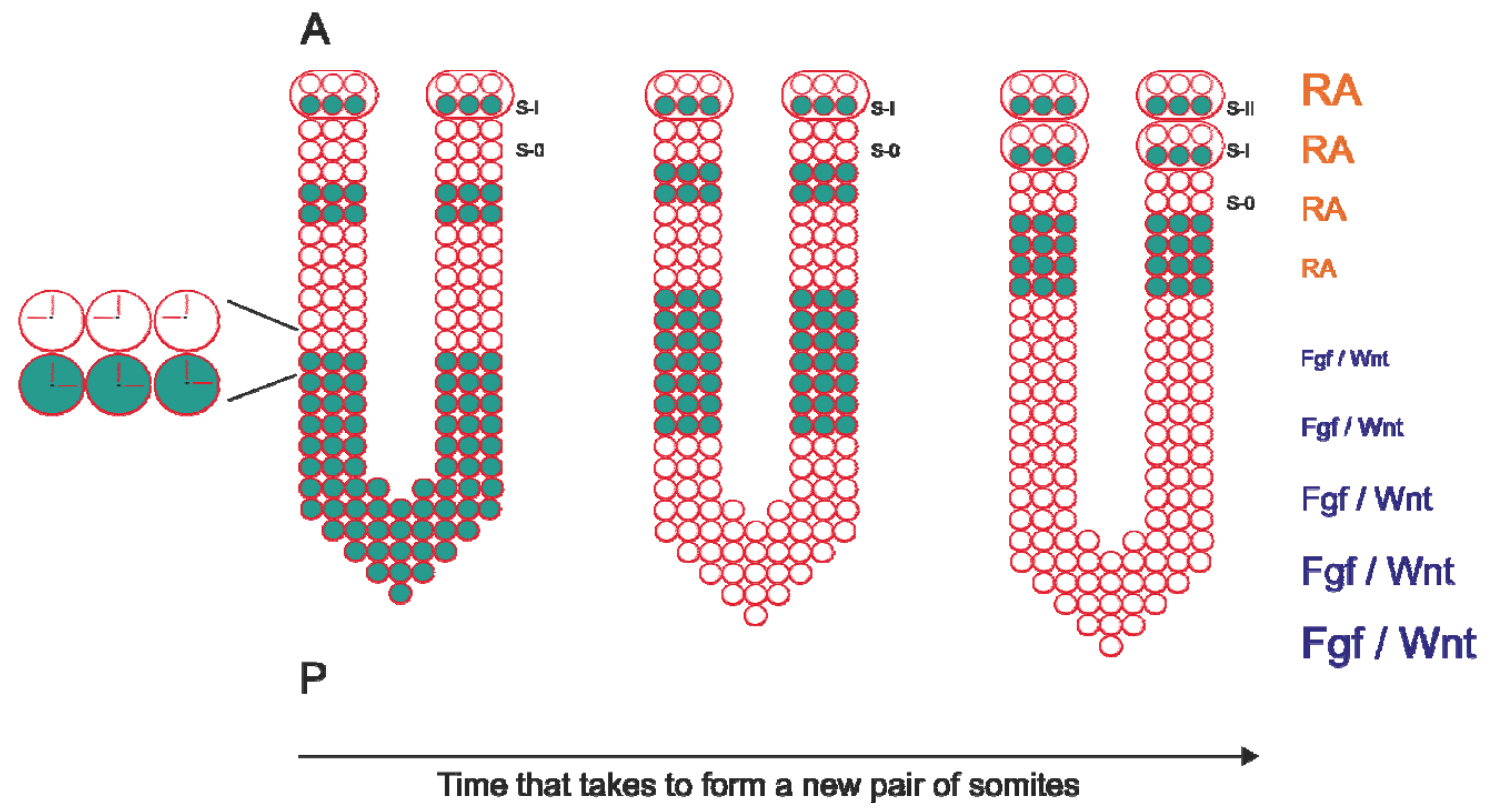

The fact that the Hairy-Enhancer of Split-related genes are targets of Notch signaling suggested that this pathway is a fundamental component of the segmentation clock. Indeed, the analysis of mouse and zebrafish mutants for several components of the Notch pathway revealed that cyclic gene expression and somite boundary formation were disrupted to varying degrees. Nevertheless, the anterior somites developed normally and only the posterior ones were affected in the Notch mutants [14-16]. These findings showed that Notch signaling is not entirely necessary for somite formation but instead suggested that its failure leads to a gradual perturbation in somite segmentation.

Furthermore, a closer look at the expression of the Notch ligand deltaC, one of the oscillatory genes in zebrafish, in Notch signaling mutants revealed that individual PSM cells still expressed deltaC in a cyclic manner, but the levels varied quite a lot between neighboring cells. This led to the idea that the main function of Notch signaling is to coordinate oscillations between individual cells and to keep them synchronized and not so much to drive the oscillations (Figure 2). Therefore, it was proposed that in zebrafish Notch mutants, PSM cells begin oscillations in synchrony forming normal anterior somites but after a few cycles gradually loose their synchrony forming abnormal somite boundaries [17]. 
Figure 2. Synchronized oscillations between adjacent cells in zebrafish presomitic mesoderm. Activation of Notch, upon interaction with DeltaC, activates the expression of her genes. her genes encode transcriptional repressors that have the ability to inhibit their own expression generating negative feedback loops that are then responsible for the PSM intracellular oscillations. Importantly, the period of these oscillations are dependent on both transcriptional (Tm) and translational delays (Tp). Her proteins will not only inhibit their own expression, but also inhibit the expression of deltaC that for this reason is also expressed in an oscillatory manner. DeltaC in one cell will then activate Notch signaling in the neighboring cell and as a consequence generates intracellular oscillations. Thus, oscillations between adjacent cells are synchronized with one another since they are coupled via Notch signaling.

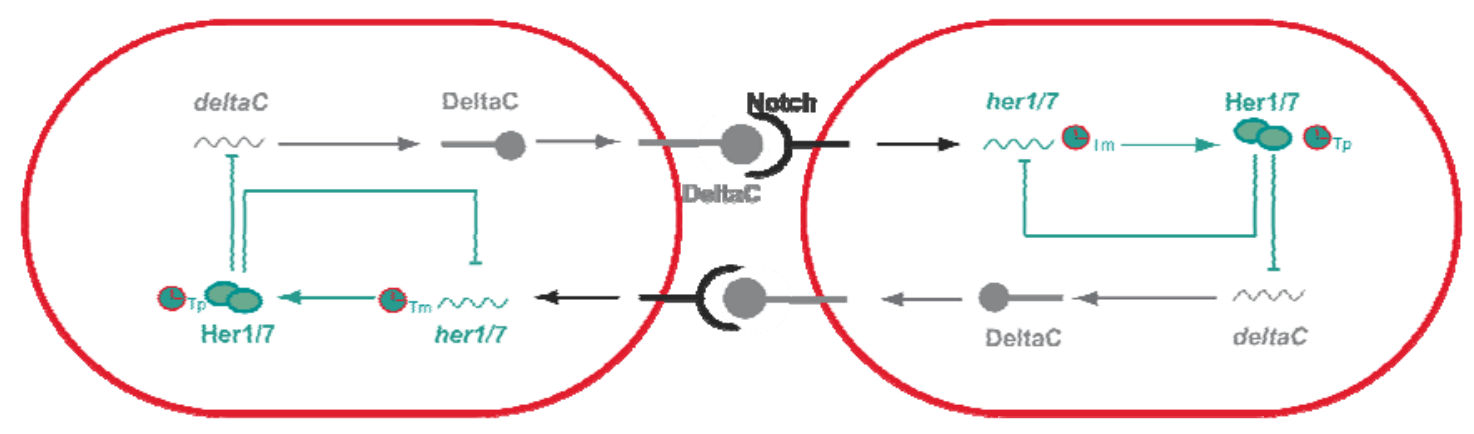

A model put forward by Lewis (2003) proposed a way by which DeltaC synchronizes oscillations between neighboring cells (Figure 2). It postulates that the intracellular negative feedback oscillations of her1/her7 genes are coupled to an intercellular oscillator involving Delta ligands. In fact, Her1/Her7 negatively regulate deltaC, influencing Notch activity in the neighboring cells and finally their own intracellular oscillations. This Delta/Notch mediated coupling mechanism results in synchronization between adjacent cells [13,18-21].

Several studies performed in zebrafish clearly demonstrated that DeltaC maintains synchronized oscillations in PSM cells. Mosaic embryos were generated by transplantation of prospective PSM cells taken from an embryo with impaired expression of the oscillatory her genes into the prospective PSM region of a wild-type embryo. In these mosaics, the transplanted cells caused an abnormal segmentation behavior in their neighbors but failed to cause segmentation defects if in addition they did not express deltaC [22]. The same type of conclusion was reached from a high-resolution in situ hybridization analysis that allowed the visualization of the distinct sub-cellular localizations of the cyclic mRNAs corresponding to their different phases of oscillations in PSM cells. In contrast to a wild-type PSM, in the absence of DeltaC, completely different mRNA localizations could be observed in PSM cells located next to each other [23]. Further support that Notch signaling serves to maintain synchrony in the PSM but is not necessary for oscillations of individual cells comes from studies where the $\gamma$-secretase inhibitor DAPT was used to block Notch signaling in a time controlled manner $[21,24]$. In these reports, it was shown that there is a delay between the time of DAPT treatment and the disruption of somite boundaries and a delay between DAPT wash and the recovery of normal somite boundaries. Altogether, these results argue, at least in zebrafish, against the idea that Notch signaling is the oscillation generator and favors the idea that its main function is to synchronize 
oscillations within the PSM cells. Recently, a detailed sub-cellular mRNA localization study, revealed that besides its role in the synchronization of oscillations in posterior PSM, Notch signaling through DeltaD is necessary to initiate non-oscillating expression of the cyclic genes and to start the oscillations in PSM progenitors located in the tail bud [23].

In contrast to what happens in zebrafish, it was recently shown that elimination of all Notch activity abolishes cyclic gene expression and somite formation in mouse PSM [25]. This finding is not incompatible with the possibility presented by others of Notch being a clock synchronizer during mouse somitogenesis [26,27] since it could integrate both functions. Although a clear demonstration that this pathway synchronizes the oscillations of PSM cells in amniotes is still missing, this could still be a possibility since perturbation of cell-cell interactions upon PSM cell dissociation in chick and mouse leads to irregular desynchronized oscillations [28,29].

The different roles that Notch signaling seems to play during mouse and zebrafish somitogenesis could be due to different degrees of complexity of the segmentation clock mechanism in these two species. A mouse transcriptome study has shown that a large number of genes are in fact oscillating in the mouse PSM. Many of these genes belong not only to the Notch pathway as expected but also to the Wnt and FGF pathways. In addition, this study also revealed that while the Notch and FGF pathway genes oscillate in synchrony, they are in anti-phase with the oscillations of the Wnt pathway genes. This points to a possible cross-talk between them in a way that Wnt pathway may be coupled to Notch and FGF through mutual inhibition, so that all are integrated in one molecular clock [30]. In zebrafish there is no evidence for the existence of Wnt or FGF-based cyclic genes [1].

\subsection{The Wavefront Sets the Position of Somite Formation}

According to the original clock and wavefront model, the regular spacing of somites is also under the control of a wavefront that sets the position where the next somite boundary is going to be formed. Indeed there are several lines of evidence that show that this position is defined by a threshold of FGF and Wnt signaling along the PSM [31,32] (Figure 1). While under the influence of FGF/Wnt signaling, the PSM cells are maintained in an immature state and are prevented from starting the genetic program of somite formation.

The posterior-to-anterior gradient of fgf8 mRNA in the PSM was the first one to be described in several vertebrate embryos (mouse, zebrafish and chick) [31,33,34]. This gradient is generated via a decay mechanism from a pool of transcripts produced by progenitor PSM cells [34]. According to the clock and wavefront model [2], displacing the position of the determination front by altering the extent of the fgf8 gradient results in the shift of the somite boundary position [31]. It is thought that this gradient is translated into a protein gradient, which is then converted into a MAPK/ERK activity gradient along the PSM [33-35].

Parallel to the $f g f$ gradient there is also a posterior-to-anterior gradient of Wnt signaling along the PSM. The expression of wnt3a in the posterior PSM [32] could be responsible for the nuclear $\beta$-catenin gradient reaching from the tailbud to the determination front [36] and for the graded expression of the Wnt target axin2 [32].

It has been proposed that the determination front established by the fgf and wht gradients is opposed by an anterior-to-posterior gradient of retinoic acid (RA) [37,38] (Figure 1). RA is the oxidized version 
of vitamin A. It is synthesized in the anterior PSM and somite region by the enzyme retinaldehyde dehydrogenase 2 (Raldh2), and degraded in the posterior PSM by the enzyme Cyp26a1 [39]. RA in the anterior PSM has been shown to control somite boundary positioning by attenuating Fgf8 in that region. These mutually inhibitory gradients and control somite differentiation by defining the determination front in a growing tissue [37].

\section{Is the Body Plan All about Symmetry?}

When looking at the exterior of a vertebrate body, one could say that it is fully bilaterally symmetric. Nonetheless, this external symmetry encloses unexpected surprises, since the internal organs acquire a consistently asymmetric disposition with respect to the left-right (LR) axis. On the left side of the vertebrate body we can find the heart, stomach, spleen and the part of the lung with fewer lobes, while on the right side we have the liver, gall bladder and the part of the lung with more lobes. This normal distribution of the internal organs is referred to as situs solitus and is largely conserved among a population of a given species. Nevertheless, deviations from the norm can arise in single individuals and will result in laterality defects: situs inversus corresponds to a situation where the position of the internal organs is completely reverted as a mirror-image; left or right isomerism is a situation where bilateral symmetry is not broken and two left or two right sides will form; situs ambiguus or heterotaxia that corresponds to some organs being properly oriented and others reversed [40,41].

Well before visible morphological asymmetries can be observed in the vertebrate embryo, a conserved cascade of asymmetrically expressed genes, called the Nodal cascade is activated at the onset of gastrulation. Genes belonging to this cascade are the TGF- $\beta$ family members, nodal, lefty 1 , lefty 2 and the homeobox transcription factor, pitx2. It is thought that an excess of Nodal activity on the left-hand side of the node will be transferred to the left lateral plate mesoderm (LPM) and in this location Nodal exerts a positive feedback on itself. Consequently, the expression of nodal is amplified in the left LPM. At the same time, nodal activates its negative regulators, the lefty genes. Lefty 1 in the midline prevents nodal activation on the right LPM, while lefty2 restricts the domain of nodal expression on the left LPM. Here, Nodal induces pitx2 expression. Pitx2 will promote LR asymmetry of the internal organs, through a mechanism not yet fully understood [42] (Figure 3C).

Although the Nodal cascade is conserved among vertebrates, the mechanism that induces nodal in the node in the first place shows differences between vertebrates. In mouse and chick, Notch signaling activates nodal in the node region $[43,44]$. In zebrafish Notch signaling activates the Nodal negative regulator charon [45] around the Kupffer's vesicle (KV), the structure analogous to the mammalian node. In addition to Notch signaling, $f g f 8$ also regulates nodal asymmetric expression in the mouse and chick node. In the mouse, $f g f 8$ acts as a positive nodal regulator and therefore is a left determinant. In the chick, $f g f 8$ is asymmetrically expressed on the right side of the node where it represses nodal, thereby acting as a right determinant [46]. The role of fgf8 in controlling expression at the KV has not been determined, although fgf8 mutants show LR defects [47]. Also Wnt signaling, namely Wnt3a, indirectly regulates nodal expression in the mouse node indirectly through Delta-like1 [48]. In the chick, wnt8c is asymmetrically expressed on the right side of the node but functions as a left determinant controlling the expression of nodal [49]. 
Figure 3. Set of events that might culminate with the establishment of the left-right patterning in different vertebrates. (A) Prior to gastrulation in Xenopus, zebrafish and chick, ion transporters asymmetrically distributed in the embryo generate differences in membrane voltage potential between the left and right side. It is thought that this asymmetric membrane polarization promotes the accumulation of LR determinants through directional transport involving gap-junction channels. (B) In mouse, it is though that mechanosensory cilia present in the node epithelia sense the leftward fluid flow created by motile cilia and as a consequence trigger an asymmetric $\mathrm{Ca}^{2+}$ release, which will induce an asymmetric nodal expression around the node. This $\mathrm{Ca}^{2+}$ accumulation on the left side has also been described in zebrafish and chick although its relation with cilia-driven flow has not been established. (C) A conserved nodal cascade is activated at the onset of gastrulation in Xenopus, zebrafish, chick and mouse. Nodal is asymmetrically transferred from the node to the left LPM. There, it induces its own expression through a positive feedback loop and also the expression of its own inhibitors, lefty 1 and lefty2. Lefty 1 is expressed in the midline and prevents nodal spreading to the right LPM, while lefty 2 is expressed in the left LPM restricting Nodal expression on the left side.
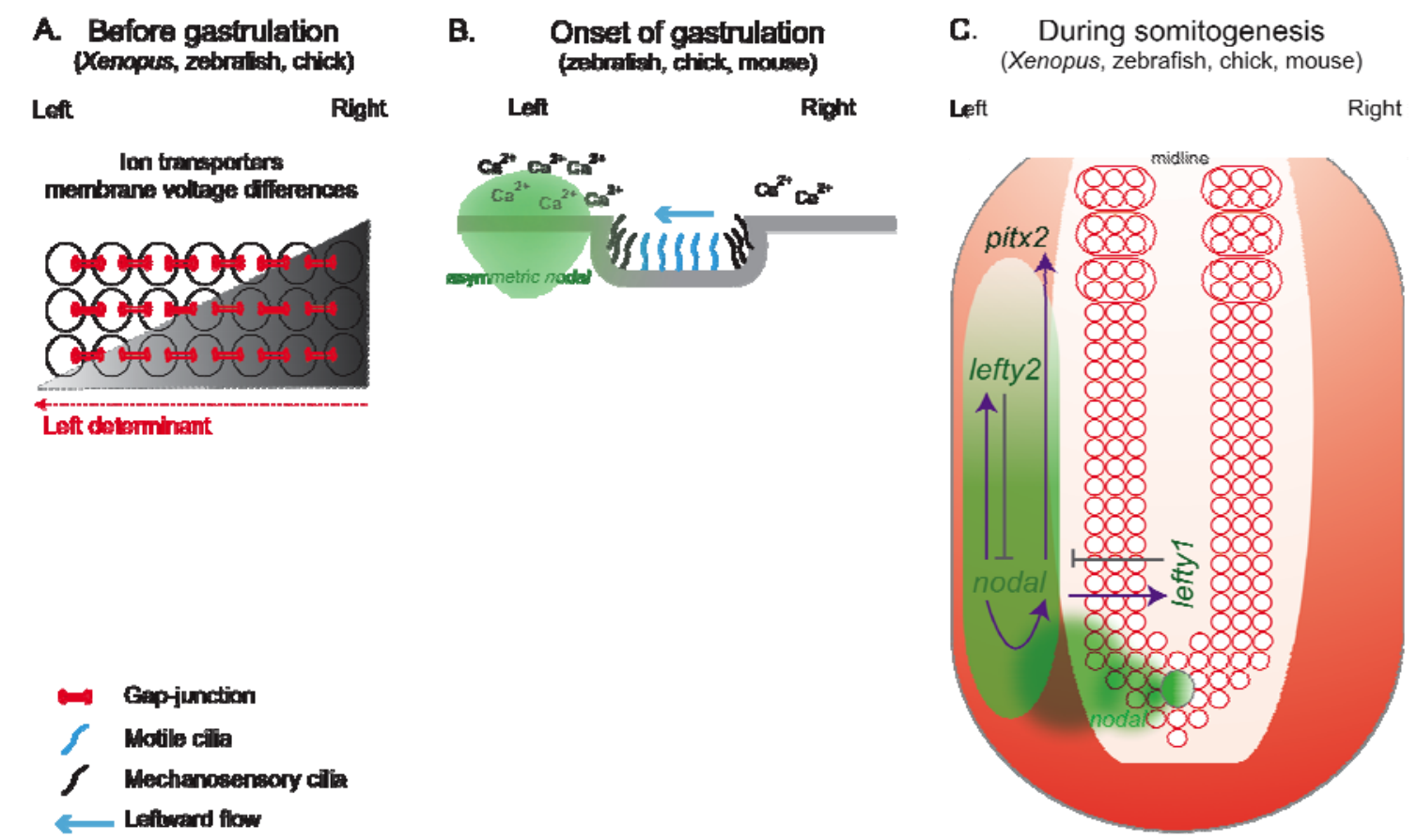

\subsection{How Can Cilia Break Symmetry?}

Apart from of the signaling pathways that might activate nodal in the node region and the subsequent signaling cascade, it is important to understand the event that turns nodal expression asymmetric on the left side of the node. In other words, how is the initial embryonic symmetry broken in the node region? A clue to start to solve this question came from the observation that Kartagener's syndrome patients have ultrastructural defects in Dynein, a component of the ciliary motion motor [50,51]. This particular defect was readily associated with the chronic respiratory infections and male infertility observed in these patients as a result of lack of cilia/flagella motility within the 
respiratory epithelium and sperm. However, the connection with situs inversus was only established later. It turned out that left-right dynein ( $I r d$ ) is expressed in the mouse node [52], that node cells possess monocilia [53] and that the inversus viscerum (iv) mutant mouse that shows a clear randomized laterality phenotype has a mutation in Ird [54-56]. Most importantly it was shown that these node cilia rotate in a clockwise manner and due to their posteriorly tilted position on each cell create a leftward extracellular fluid flow that induces left-side specific gene expression [57,58] (Figure 3B). The reversed laterality obtained when an artificial rightward flow is imposed on the mouse node is consistent with the idea that a directional fluid flow provides the asymmetry cue that determines laterality [59]. Moreover, using the same experimental setup, it was possible to rescue the laterality phenotype of the iv mouse mutant, in which no flow is observed by simply exposing their nodes to a strong leftward fluid flow $[59,60]$.

How the flow is interpreted and then converted into LR asymmetric gene expression is still unknown. Nevertheless, two models have been proposed to date. One model states that a morphogen might be transported as a consequence of the leftward fluid flow created by motile Ird-containing cilia. The resulting asymmetric morphogen distribution would initiate downstream molecular events that then establish left-right asymmetries in the LPM [57]. More recently, vesicular particles containing Sonic hedgehog (Shh) and retinoic acid (RA) were shown to form in the node stimulated by FGF and are transported to the left edge of the node where they fragment and release their contents [61]. An alternative model mentions the existence of two different subpopulations of cilia in the node. In addition to the motile Ird-containing cilia, there are also immotile mechanosensory cilia containing the polycystin-2 calcium activated channel $[62,63]$. It has been proposed that immotile mechanosensory cilia sense the fluid flow pressure on the left side of the node and trigger an asymmetric intracellular $\mathrm{Ca}^{2+}$ flux that then breaks LR symmetry by inducing asymmetric nodal expression [62] (Figure 3B). These two models are not mutually exclusive and it is possible that both mechanosensors and morphogens are involved in setting up the asymmetric pathway.

\subsection{More than Cilia: Other Players in the Scene}

Although, first described in mouse, the directional flow produced by motile cilia in the node is not exclusive to murine embryos. In fact a directional type of flow is generated in node-equivalent structures in a wide range of vertebrates. In zebrafish and medaka, the motile cilia inside the KV produce a counterclockwise fluid flow. Moreover, when cilia motility is impaired, fluid flow is abolished and LR development is perturbed [64-67]. The rabbit posterior notochord (PNC) and Xenopus gastrocoel roof plate (GRP) also have motile cilia, which have been shown to create a leftward fluid flow [68-70]. As for the chick, it is clear that ciliated cells are present in the Hensen's node. However no directional flow has been described in the chick node possibly because the distance between single monocilia is too long to create a directional flow thus compromising their role in LR determination [71,72]. Instead, it seems that asymmetry in the node is promoted by outside tissues [73], most likely through asymmetric cell rearrangements that generate a leftward movement of cells around the node [74,75]. 
Although it is clear that monocilia play a fundamental role in LR patterning, several lines of evidence suggest that earlier LR asymmetries already exist prior to the directional fluid flow generated by ciliary motion, at least in amphibians, chick and fish.

In Xenopus, an asymmetrically localized ion flux is set up through an $\mathrm{H}^{+} / \mathrm{K}^{+}$ATPase transporter (pumps $\mathrm{H}^{+}$out of the cell in exchange for $\mathrm{K}^{+}$). In fact, $\mathrm{H}^{+} / \mathrm{K}^{+}$ATPase maternal mRNA is already asymmetrically localized on the right-hand side of the embryo during the first two cell divisions. In addition, it was shown that inhibition of this pump results in randomization of left side specific genes and organ heterotaxia [76]. It has been suggested that asymmetric ion flux might be responsible for directing the positioning of a LR determinant to the left side through gap junction communication channels (GJC) since inhibition of these channels induces heterotaxia in Xenopus [76,77]. Generation of LR voltage differences that control laterality also seem to be important in the chicken embryo. In fact, a differential $\mathrm{H}^{+} / \mathrm{K}^{+}$ATPase activity across Hensen's node results in left side asymmetric ion flux, which creates a differential membrane potential between the left and right sides of the primitive streak. Asymmetric ion flux has also been suggested to direct LR determinants through GJC in chick, since GJC inhibition also leads to LR patterning problems [76,78]. $\mathrm{H}^{+} / \mathrm{K}^{+}$ATPase activity results in extracellular $\mathrm{Ca}^{2+}$ accumulation on the left side of Hensen's node, a possible candidate for being a LR determinant molecule that passes through the GJC. In fact, $\mathrm{Ca}^{2+}$ accumulation was shown to induce an asymmetric activation of Notch on the left side of the node that then translates this differential activity into asymmetric nodal expression. Perturbing this early asymmetric ion flux, will lead to randomized gene expression and organ heterotaxia [44]. In zebrafish it has been shown that the early activity of the $\mathrm{H}^{+} / \mathrm{K}^{+}$ATPase pump determines the LR axis without affecting cilia or KV fluid flow [79]. More recently, the function of another proton pump, the $\mathrm{H}^{+}-\mathrm{V}$-ATPase, was shown to be important to establish LR asymmetries in Xenopus, fish and chick and in the case of zebrafish clearly impacts on cilia size/number within the KV [80]. In zebrafish, another pump, the Na,K-ATPase alpha2, modulates the levels of intracellular $\mathrm{Ca}^{2+}$ already in the cells that are going to give rise to the $\mathrm{KV}$, the dorsal forerunner cells (DFC's). In turn, these $\mathrm{Ca}^{2+}$ levels regulate cilia motility in the $\mathrm{KV}$ and consequently the cilia-driven leftward fluid flow [81]. Propagation of the intracellular asymmetric $\mathrm{Ca}^{2+}$ flux is regulated by inositol polyphosphates, which in turn are candidates for the LR determinant that passes through GJC and influence LR determination [82]. Consistent with this idea, Connexin43.4 (Cx43.4), a protein of the GJC channel, is required for the LR patterning through the development of a functional KV with normal cilia [83].

Another possible candidate for the LR determinant is the neurotransmitter serotonin, which has been demonstrated to regulate LR patterning in Xenopus and chick before the appearance of cilia. Maternal serotonin has a rightward gradient localization during cleavage stages and its localization requires the set up of an asymmetric voltage gradient created by the $\mathrm{H}^{+} / \mathrm{K}^{+}$ATPase coupled with GJC channels $[84,85]$.

Although the fluid flow generated by cilia seems to be the first symmetry-breaking event in mouse, it may not be the initial event in other organisms where it is more likely to serve as an amplification mechanism of the LR decision made earlier in development. In zebrafish, Xenopus and chick, different mechanisms seem to act prior to the leftward flow initiation, such as asymmetric localization of ion channels and asymmetric function of gap junctions (Figure 3A). So far, no ion transporters or gap junctions have been described to be involved in LR establishment in mammals, however there is still 
the possibility that an unidentified symmetry breaking event may occur earlier in mouse development. Interestingly, a recent report states that manipulation of initial cleavages in the mouse embryo leads to a reverted direction of fetal axial rotation, although the heart and gut laterality was not affected [86]. This finding sets the ground for the possibility that in mammals LR embryonic patterning may be set during the cleavage stages similarly to what has been described in snails, where manipulation of the first cleavages resulted in reverted shell coiling and visceral situs inversus [87].

\section{How Are Symmetric Tissues Protected from LR Asymmetric Signals?}

The formation of a perfect vertebrate body plan involves the establishment of LR asymmetries in the LPM to position the internal organs. In addition, it is also crucial that bilateral symmetry is maintained in the PSM ensuring the symmetric formation of the somites and consequently of the axial skeleton and skeletal muscles. Besides sharing the same signaling pathways as discussed above, somitogenesis and LR patterning take place at around the same time during development in nearby embryonic regions. Therefore, the asymmetric signals that originate in the node have to be able to influence the LPM without affecting the bilateral symmetry of somite formation in the juxtaposed PSM. In fact, several lines of evidence show that bilateral symmetry is not a default state but instead has to be actively maintained through a mechanism that protects this territory from the LR asymmetric signals [88].

\subsection{Retinoic Acid Buffers the PSM from the Influence of LR Signals}

RA binds to heterodimers of retinoic acid receptor (RAR) and retinoid X receptor (RXR) and activates transcription of RA-responsive genes upon binding to specific DNA sequences known as retinoic acid response elements (RAREs) [89]. RA has been implicated in the control of bilateral symmetry in vertebrates, acting as a buffer that prevents LR signals to reach the PSM and influence somitogenesis (Figure 4A).

When the function of the RA producing enzyme raldh2 is abolished either by a null mutation in the mouse or by morpholino-knockdown in zebrafish embryos, somite formation is delayed with a bias on the right side as assayed by the expression of uncx4.1, a marker of the posterior half of the mature somite [79,90] (Figure 4B). In the neckless mutant, that carry a missense mutation in raldh2, the same phenotype is observed [79]. Interestingly, the somitogenesis delay on the right side observed in the raldh2 mutants and morphants only happens in a specific time window, between $8-15$ somite stage in mouse and 6-13 somite stage in zebrafish. The reason for this particular time window lies on the fact that these somites derive from progenitor PSM cells that were near the node/KV when the LR information was being transferred earlier from the node/KV to the LPM [91,92]. The delay in somite formation in not caused by a defect in LR patterning in general, since no laterality defects are observed in the absence of raldh2 in mouse and zebrafish [79,90,93]. In addition, epistatic experiments by crossing the raldh2 with lrd mouse mutants lead to randomized somite defects instead of the right biased defects seen in raldh2 single mutants [94]. This particular experiment shows that RA acts to counteract LR signals.

The right biased somite defects seen in the absence of raldh2 can be explained by the LR desynchronization of the segmentation clock [79,90] (Figure 4B). In these embryos, the expression of 
the cyclic genes hes7 and lfng (in mouse), deltaC, her1 and her7 (in zebrafish) are out of phase between the left and right sides. Also consistent with the somite phenotype is the anterior displacement of the wavefront seen by the anterior expansion of fgf8 on the right side of the PSM. These LR desynchronization defects are only detected within a small time window that correlates with asymmetric somite formation $[79,90]$.

Figure 4. Protection of PSM segmentation from LR asymmetric patterning cues. (A) PSM is protected from LR signals that come from the node and are implicated in left-right patterning (red arrows). This protection consists of a "shield" (white) which so far has been shown to be composed of RA, Snail, $\mathrm{Su}(\mathrm{H})$ and Terra. In its presence, cyclic gene expression (blue) and somite formation are symmetric between the left and right sides; (B) In the absence of this protection, cyclic gene expression becomes desynchronized between both sides. Consequently, somite formation proceeds in an asymmetric way, with the left side exhibiting more somites than the right (this biased asymmetry towards the right side is seen in mouse and fish embryos, while in chick asymmetries are biased to the left side).
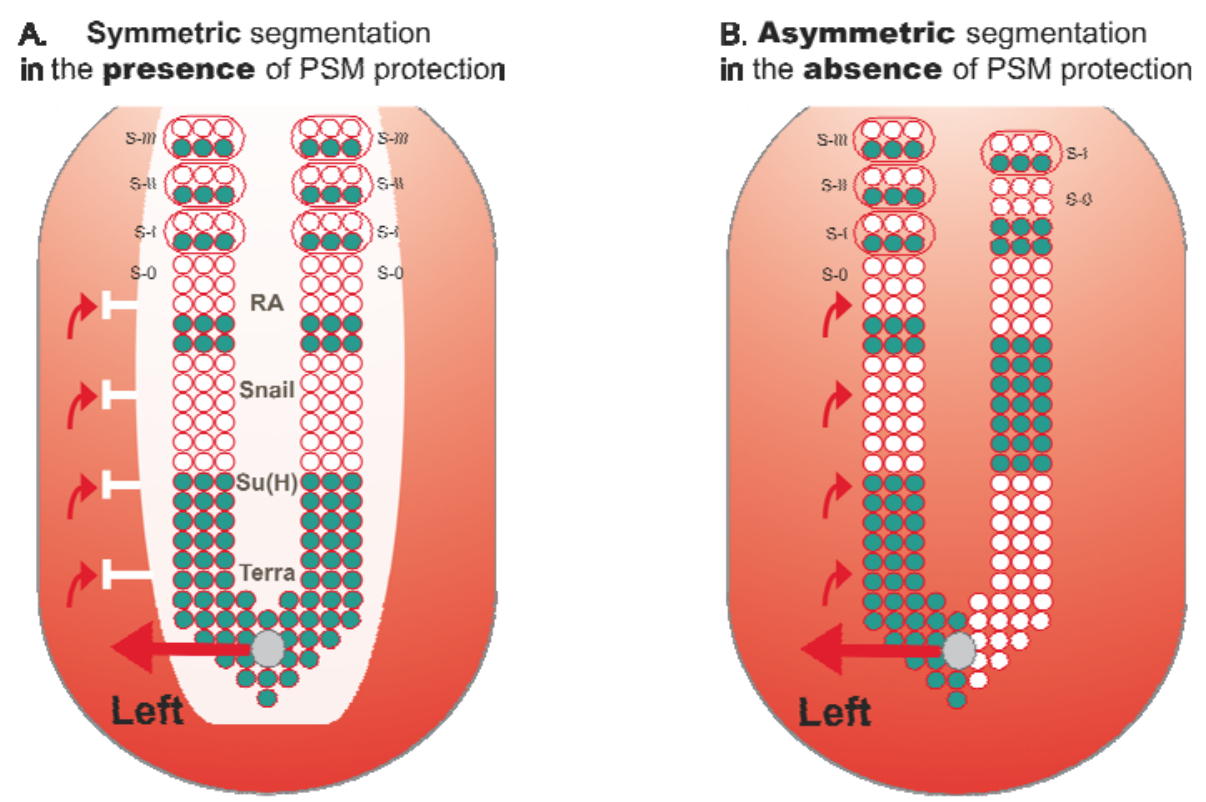

When raldh2 was inhibited with disulphiram in chick embryos, again a delay in somite formation was observed and this effect was restricted to a specific time window. But in contrast to mouse and zebrafish fewer somites are formed on the left side of the axis [94]. The segmentation clock is in different phases between the left and the right side of PSM, as seen by the asymmetric expression of lfng. However in contrast to mouse and zebrafish, fgf8 does not show a clear expansion anteriorly in an asymmetric manner in disulphiram-treated chick embryos, suggesting that wavefront may not be responsible for asymmetric somite formation [94].

Thus, RA has a conserved function which is vital for symmetric somite formation, by protecting the PSM form the LR cues that are being transferred from the node into the LPM during a specific period of time (Figure 4A). After this discovery the next question that arises is what are the LR cues that RA is counteracting and where and when is this action being performed? Due to the fact that radlh2 is 
expressed in the PSM it is reasonable to predict that RA is performing its function in this mesodermal tissue. However, using a retinoic-acid response element (RARE)-LacZ-reporter transgene it was shown that RA signaling in mouse embryos is present not only in somites and anterior PSM, but it also extends to the adjacent neural plate and the node ectoderm [93]. In the node ectoderm, RA antagonizes fgfo that is expressed nearby in the epiblast (primitive ectoderm). In raldh2 mutants already at early somite stages there is an expansion of $f g f 8$ expression from the epiblast into the neural plate and node ectoderm. At later stages, these embryos show a right shift of fgf8 expression in the anterior PSM, suggesting that the expansion of $f g f 8$ into the node ectoderm may be increasing its own levels in the adjacent PSM shifting it more anteriorly [93]. These authors suggest that RA is ensuring bilateral somite formation not at the level of the PSM but at the level of the node ectoderm, where it controls the limits of $f g f 8$.

Recently, an independent study using the same (RARE)-LacZ-reporter transgene showed however that the levels of RA signaling in the mouse PSM are higher on the right side [95]. In addition, these authors show that this asymmetric RA signaling results from the function of a complex consisting of $\mathrm{Nr} 2 \mathrm{f} 2 \mathrm{a}$ and a novel RA signaling component called Rere. While rere is ubiquitously expressed, $n r 2 f 2 a$ is asymmetrically expressed on the right PSM. In mice mutant for Rere, there is a lack of LR synchronization of the cyclic genes and of the fgfo anterior limit in the PSM, leading to a somitogenesis defect similar to the one described for raldh2 mutants. This asymmetric RA signaling seems to be important to control the LR determination function of fgf8 in the PSM. Interestingly, $n r 2 f 2 \mathrm{a}$ expression in the mouse is asymmetric on the right, while in the chick it is asymmetric on the left side of the PSM. This provides an explanation for the different bias in the somite formation defects observed in the absence of RA signaling in these two vertebrates [94,95] and might be linked with the fact that $f g f 8$ is a left determinant in the mouse while in the chick it is a right determinant $[46,96]$.

Fgf8 does not seem to be the only LR cue corrected by RA signaling. In both chick and mouse embryos, snail1 is transiently asymmetrically expressed in the right LPM and plays a role in organ lateralization [97,98]. Furthermore, it was shown that the period of asymmetric snail1 expression in the LPM coincides with the time window during which RA is necessary to protect the PSM from asymmetric signals [99]. Indeed, in the chick it was shown that in the absence of RA signaling, snail1 expression is not affected in the LPM but starts to be asymmetrically expressed in the right anterior PSM. This asymmetric PSM expression of snail1 results in asymmetric expression of the cyclic genes snail2 and Ifng and later leads to asynchronous somitogenesis [99]. In mouse, asymmetric somite formation seen in the absence of RA signaling [94] may be due to a misregulation of snail1 expression in the PSM, since it has been shown that in mice mutants for Rere there is an asymmetric snail1 expression in the PSM [95].

RA perturbation does not result in LR defects in the LPM since the expression of spaw and pitx2 in the LPM is normal. However, the somite laterality defects are linked to the LR pathway. In fact, the bias in somite defects is lost in raldh2/lrd double mutants where RA signaling is perturbed together with randomization of the LR asymmetric cues [79,94,95].

Perturbations of RA function lead to a biased somitogenesis defect in a specific time window that correlates with the timing of LR cues establishment $[79,94,95]$. Therefore, RA signaling has emerged as a conserved keeper of bilateral somite formation. 


\subsection{Bridge between LR Patterning and Somitogenesis}

Direct links between LR patterning and somitogenesis were revealed in studies in zebrafish. The transcription factor Suppressor of Hairless $(\mathrm{Su}(\mathrm{H}))$, belongs to a complex that mediates Notch signaling [100]. The downregulation of any of the two $\mathrm{Su}(\mathrm{H})$ paralog genes in zebrafish leads to randomization of LR markers in the LPM and to an unbiased asymmetric somite formation. In the $s u(H)$ morphants, the RA degrading enzyme cyp26a1 is misregulated in the tailbud. Since cyp26a1 knockdown can also lead to asymmetric cycling gene expression, this suggests that $\mathrm{Su}(\mathrm{H})$ is required to regulate RA in the tailbud that will in turn regulate symmetric cycling gene expression in the PSM [101] (Figure 4A, B).

We have shown that Dmrt2a/Terra, a zinc finger-like transcription factor belonging to the DMRT (DM Related Transcription Factor) family, regulates the body plan along the LR axis in zebrafish. In Dmrt2a/Terra morphants, the LR asymmetry pathway is also affected, with the expression of left side LPM markers being randomized and consequently affecting the positioning of the heart. On the other hand, dynamic cyclic expression of deltaC, her1 and her7 becomes desynchronized between the left and right sides of the PSM in a specific time window, leading to an unbiased somite number. Therefore, Dmrt2a/Terra has a dual role, it ensures the correct flow of LR asymmetry information to the LPM and in combination with RA signaling ensures the maintenance of symmetry in the PSM [102] (Figure 4A, B). In the mouse, the knockout of dmrt2 strongly affected somite differentiation leading to severe rib and vertebral malformations [103]. It would be interesting to know whether it also regulates synchronization of the clock genes and if it has an impact on heart laterality.

Even more striking is the observation that the simple disruption of the LR determination pathway results in asymmetric somite formation in zebrafish. Downregulation of the $\mathrm{H}^{+} / \mathrm{K}^{+}$-ATPase activity, with omeoprazole from 1-cell to bud stages only, results in randomization of LR markers in the LPM and in an unbiased asymmetric somite formation between the left and right sides of the PSM [79]. Also when Notch signaling is perturbed, with the $\gamma$-secretase inhibitor DAPT from bud to early somitogenesis stages, there is a randomization of LR markers in the LPM and an unbiased asymmetric somite formation. Once again the somitic defects are only detected in a specific time window from 6 to 13 -somite stage, corresponding to the moment when LR information is being transferred from the KV to the LPM cascade [79].

At this moment, there is no evidence for the existence of a LR desynchronization phenotype in somite formation upon perturbation of early LR asymmetric information in mouse laterality mutants. Since the bilateral somite phenotype can only be detected in a specific time window, there is still the possibility that it was not noticed over the extensive organ laterality analysis.

\section{Human Developmental Disorders Related to the LR Axis}

The set-up of the axial skeleton is dependent on somite formation and differentiation. After epithelialization from the anterior region of the PSM, each somite undergoes a dorsal-ventral compartmentalization so that the ventral region, enclosing the sclerotome, is different from the dorsal region, the dermomyotome. This subdivision is important for later patterning events, with the sclerotome differentiating into the axial skeleton and ribs, and the dermomyotome giving rise to the 
dermis of the back and skeletal muscles [104]. A diverse number of human conditions associated with vertebral malformations arise as a consequence of mutations in important somitogenesis-related genes. Mutations in Notch ligand delta-like 3 (dll3) [105], mesp2 [106] and lfng [107] are associated with the spondylocostal dysostosis syndrome. This condition exhibits vertebral column malformations from rib fusions to kypho-scoliosis (abnormal curvature of the spine). This phenotype is reminiscent of what happens in mouse mutants, highlighting the importance of mouse models in the search for the genes associated with human disorders [108-110]. Mutations in other genes of the Notch pathway can also lead to vertebral malformations. Mutations in two Notch pathway ligands, jag1 and notch2, are associated with the Alagille syndrome which has been shown to present, among other symptoms, abnormal vertebrae formation with a "butterfly shaped" [111]. Fgf signaling has also been implicated in disorders associated with skeletal development. A mutation in fgfr2 results in fused cervical vertebrae, known as the Apert syndrome [112]. A minor perturbation in segmentation can lead to severe clinical consequences. Thus the identification of molecules that can reduce vertebral patterning disorders will subsequently help in their prevention.

LR asymmetric cues are important to position the internal organs in a normal configuration termed situs solitus. When LR patterning is disturbed by a series of events, as previously discussed, abnormal laterality phenotypes appear namely situs inversus and situs ambiguus. The morbidity and mortality associated with laterality defects is mainly due to congenital heart disease (CHD) [113]. Human patients with situs inversus have 3\% incidence of CHD compared with normal situs solitus humans that show a $0.08 \%$ incidence [114-116]. In situs ambiguus patients the incidence of CHD is greater than 90\% [115]. The cardiac defects in these patients include atrial and ventricular septal defects, transposition of great arteries, double outlet right ventricle, anomalous venous return and aortic arch anomalies [117]. The clinical observations together with a number of molecular evidence from animal models are helping to understand the ethiology of CHD. It is becoming clear that heart diseases may result from abnormal looping and remodeling of the primitive heart tube into a multi-chambered organ as a consequence of LR patterning defects.

In addition, human laterality defects are associated with primary cilia dyskinesia (PCD), which is characterized by deficiencies in ciliary motility. In PCD patients, 47.7\% display situs inversus, 6.3\% display situs ambiguus or heterotaxy, most of them also presenting cardiovascular abnormalities, while the remaining $46 \%$ show normal organ situs [50,118,119]. Once again, clinical data together with experimental results from animal models provided a biological explanation for this association, revealing that cilia are indeed early players in LR patterning.

It should be noticed that laterality defects in humans are often associated with abnormal vertebrae and scoliosis [120]. The genetic etiology of these conditions is unknown, however we speculate that they may relate to the recently uncovered molecular link between LR patterning and bilateral synchronization of the segmentation clock.

\section{Conclusions}

To design the vertebrate body plan it is fundamental to create asymmetry between the left and the right side of the lateral plate mesoderm, in order to correctly position the internal organs. Also, it is crucial to maintain symmetry between the left and the right side of the presomitic mesoderm to ensure 
the perfect allocation of symmetric body structures such as the axial skeleton, skeletal muscles and peripheral nerves. Although different strategies were shown to initiate the left-right asymmetry in the vertebrate embryo [121], only recently the existence of mechanisms that promote symmetry have been described in several organisms $[90,94,79,102]$. Therefore, symmetry is no longer perceived as a default embryonic state but rather as a developmental process involving an active molecular mechanism. Although the mechanism that bridges LR patterning and bilateral synchronization of the segmentation clock is not understood, the new studies here reviewed point to the idea that a correct flow of LR signals is necessary for bilateral somite formation.

\section{Acknowledgements}

We are grateful to A. Hanisch, R. Andrade, A.T. Tavares, S.S. Lopes, R. Fior, S. Pascoal and N. Afonso for comments on the manuscript. R.L. was supported by a FCT fellowship (SFRH/BD/24861/2005). R.L. and L.S. were supported by two FCT grants (PTDC/SAU-OBD/71596/2006 and PTDC/SAU-OBD/64628/2006).

\section{References and Notes}

1. Dequéant, M.L.; Pourquié, O. Segmental patterning of the vertebrate embryonic axis. Nat. Rev. Genet. 2008, 9, 370-382.

2. Cooke, J.; Zeeman, E.C. A clock and wavefront model for control of the number of repeated structures during animal morphogenesis. J. Theor. Biol. 1976, 58, 455-476.

3. Palmeirim, I.; Henrique, D.; Ish-Horowicz, D.; Pourquie, O. Avian hairy gene expression identifies a molecular clock linked to vertebrate segmentation and somitogenesis. Cell 1997, 91, 639-648.

4. Kageyama, R.; Ohtsuka, T.; Kobayashi, T. The Hes gene family: Repressors and oscillators that orchestrate embryogenesis. Development 2007, 134, 1243-1251.

5. Hirata, H.; Yoshiura, S.; Ohtsuka, T.; Bessho, Y.; Harada, T.; Yoshikawa, K.; Kageyama, R. Oscillatory expression of the bHLH factor Hes1 regulated by a negative feedback loop. Science 2002, 298, 840-843.

6. Oates, A.C.; Ho, R.K. Hairy/E(spl)-related (Her) genes are central components of the segmentation oscillator and display redundancy with the Delta/Notch signaling pathway in the formation of anterior segmental boundaries in the zebrafish. Development 2002, 129, 2929-2946.

7. Holley, S.A.; Jülich, D.; Rauch, G.J.; Geisler, R.; Nüsslein-Volhard, C. Her1 and the notch pathway function within the oscillator mechanism that regulates zebrafish somitogenesis. Development 2002, 129, 1175-1183.

8. Dale, J.K.; Maroto, M.; Dequeant, M.L.; Malapert, P.; McGrew, M.; Pourquie, O. Periodic notch inhibition by lunatic fringe underlies the chick segmentation clock. Nature 2003, 421, 275-278.

9. Bessho, Y.; Hirata, H.; Masamizu, Y.; Kageyama, R. Periodic repression by the bHLH factor Hes7 is an essential mechanism for the somite segmentation clock. Genes. Dev. 2003, 17, 1451-1456.

10. Hirata, H.; Bessho, Y.; Kokubu, H.; Masamizu, Y.; Yamada, S.; Lewis, J.; Kageyama, R. Instability of Hes7 protein is crucial for the somite segmentation clock. Nat. Genet. 2004, 36, 750-754. 
11. Sieger, D.; Tautz, D.; Gajewski, M. The role of Suppressor of Hairless in Notch mediated signalling during zebrafish somitogenesis. Mech. Dev. 2003, 120, 1083-1094.

12. Brend, T.; Holley, S.A. Expression of the oscillating gene her1 is directly regulated by Hairy/Enhancer of Split, T-box, and Suppressor of Hairless proteins in the zebrafish segmentation clock. Dev. Dyn. 2009, 238, 2745-2759.

13. Lewis, J. Autoinhibition with transcriptional delay: A simple mechanism for the zebrafish somitogenesis oscillator. Curr. Biol. 2003, 13, 1398-1408.

14. Conlon, R.A.; Reaume, A.G.; Rossant, J. Notch1 is required for the coordinate segmentation of somites. Development 1995, 121, 1533-1545.

15. Huppert, S.S.; Ilagan, M.X.; De Strooper, B.; Kopan, R. Analysis of Notch function in presomitic mesoderm suggests a gamma-secretase-independent role for presenilins in somite differentiation. Dev.Cell. 2005, 8, 677-688.

16. Van Eeden, F.J.; Granato, M.; Schach, U.; Brand, M.; Furutani-Seiki, M.; Haffter, P.; Hammerschmidt, M.; Heisenberg, C.P.; Jiang, Y.J.; Kane, D.A.; Kelsh, R.N.; Mullins, M.C.; Odenthal, J.; Warga, R.M.; Allende, M.L.; Weinberg, E.S.; Nüsslein-Volhard, C. Mutations affecting somite formation and patterning in the zebrafish, Danio rerio. Development 1996, 123, 153-164.

17. Jiang, Y.J.; Aerne, B.L.; Smithers, L.; Haddon, C.; Ish-Horowicz, D.; Lewis, J. Notch signalling and the synchronization of the somite segmentation clock. Nature 2000, 408, 475-479.

18. Oates, A.C.; Ho, R.K. Hairy/E(spl)-related (Her) genes are central components of the segmentation oscillator and display redundancy with the Delta/Notch signaling pathway in the formation of anterior segmental boundaries in the zebrafish. Development 2002, 129, 2929-2946.

19. Giudicelli, F.; Ozbudak, E.M.; Wright, G.J.; Lewis, J. Setting the tempo in development: An investigation of the zebrafish somite clock mechanism. PLoS Biol. 2007, 5, e150.

20. Jülich, D.; Hwee Lim, C.; Round, J.; Nicolaije, C.; Schroeder, J.; Davies, A.; Geisler, R.; Lewis, J.; Jiang, Y.J.; Holley, S.A. Beamter/deltaC and the role of Notch ligands in the zebrafish somite segmentation, hindbrain neurogenesis and hypochord differentiation. Dev. Biol. 2005, 286, 391-404.

21. Ozbudak, E.M.; Lewis, J. Notch signalling synchronizes the zebrafish segmentation clock but is not needed to create somite boundaries. PLoS Genet. 2008, 4, e15.

22. Horikawa, K.; Ishimatsu, K.; Yoshimoto, E.; Kondo, S.; Takeda, H. Noise-resistant and synchronized oscillation of the segmentation clock. Nature 2006, 441, 719-723.

23. Mara, A.; Schroeder, J.; Chalouni, C.; Holley, S.A. Priming, initiation and synchronization of the segmentation clock by deltaD and deltaC. Nat. Cell Biol. 2007, 9, 523-530.

24. Riedel-Kruse, I.H.; Müller, C.; Oates, A.C. Synchrony dynamics during initiation, failure, and rescue of the segmentation clock. Science 2007, 317, 1911-1915.

25. Ferjentsik, Z.; Hayashi, S.; Dale, J.K.; Bessho, Y.; Herreman, A.; De Strooper, B.; del Monte, G.; de la Pompa, J.L.; Maroto, M. Notch is a critical component of the mouse somitogenesis oscillator and is essential for the formation of the somites. PLoS Genet. 2009, 5, e1000662.

26. Aulehla, A.; Pourquié, O. Oscillating signaling pathways during embryonic development. Curr. Opin. Cell Biol. 2008, 20, 632-637. 
27. Feller, J.; Schneider, A.; Schuster-Gossler, K.; Gossler, A. Noncyclic Notch activity in the presomitic mesoderm demonstrates uncoupling of somite compartmentalization and boundary formation. Genes Dev. 2008, 22, 2166-2171.

28. Maroto, M.; Dale, J.K.; Dequéant, M.L.; Petit, A.C.; Pourquié, O. Synchronised cycling gene oscillations in presomitic mesoderm cells require cell-cell contact. Int. J. Dev. Biol. 2005, 49, 309-315.

29. Masamizu, Y.; Ohtsuka, T.; Takashima, Y.; Nagahara, H.; Takenaka, Y.; Yoshikawa, K.; Okamura, H.; Kageyama, R. Real-time imaging of the somite segmentation clock: Revelation of unstable oscillators in the individual presomitic mesoderm cells. Proc. Natl. Acad. Sci. USA 2006, 103, 1313-1318.

30. Dequéant, M.L.; Glynn, E.; Gaudenz, K.; Wahl, M.; Chen, J.; Mushegian, A.; Pourquié, O. A complex oscillating network of signaling genes underlies the mouse segmentation clock. Science 2006, 314, 1595-1598.

31. Dubrulle, J.; McGrew, M.J.; Pourquié, O. FGF signaling controls somite boundary position and regulates segmentation clock control of spatiotemporal Hox gene activation. Cell 2001, 106, 219-232.

32. Aulehla, A.; Wehrle, C.; Brand-Saberi, B.; Kemler, R.; Gossler, A.; Kanzler, B.; Herrmann, B.G. Wnt3a plays a major role in the segmentation clock controlling somitogenesis. Dev. Cell 2003, 4, 395-406.

33. Sawada, A.; Shinya, M.; Jiang, Y.J.; Kawakami, A.; Kuroiwa, A.; Takeda, H. Fgf/MAPK signalling is a crucial positional cue in somite boundary formation. Development 2001, 128, 4873-4880.

34. Dubrulle, J.; Pourquié, O. fgf8 mRNA decay establishes a gradient that couples axial elongation to patterning in the vertebrate embryo. Nature 2004, 427, 419-422.

35. Delfini, M.C.; Dubrulle, J.; Malapert, P.; Chal, J.; Pourquié, O. Control of the segmentation process by graded MAPK/ERK activation in the chick embryo. Proc. Natl. Acad. Sci. USA 2005, 102, 11343-11348.

36. Aulehla, A.; Wiegraebe, W.; Baubet, V.; Wahl, M.B.; Deng, C.; Taketo, M.; Lewandoski, M.; Pourquié, O. A beta-catenin gradient links the clock and wavefront systems in mouse embryo segmentation. Nat. Cell Biol. 2008, 10, 186-193.

37. Diez del Corral, R.; Olivera-Martinez, I.; Goriely, A.; Gale, E.; Maden, M.; Storey, K. Opposing FGF and retinoid pathways control ventral neural pattern, neuronal differentiation, and segmentation during body axis extension. Neuron 2003, 40, 65-79.

38. Moreno, T.A.; Kintner, C. Regulation of segmental patterning by retinoic acid signaling during Xenopus somitogenesis. Dev. Cell 2004, 6, 205-218.

39. Swindell, E.C.; Thaller, C.; Sockanathan, S.; Petkovich, M.; Jessell, T.M.; Eichele, G. Complementary domains of retinoic acid production and degradation in the early chick embryo. Dev. Biol. 1999, 216, 282-296.

40. Fliegauf, M.; Benzing, T.; Omran, H. When cilia go bad: Cilia defects and ciliopathies. Nat. Rev. Mol. Cell Biol. 2007, 8, 880-893.

41. Gerdes, J.M.; Davis, E.E.; Katsanis, N. The vertebrate primary cilium in development, homeostasis, and disease. Cell 2009, 137, 32-45. 
42. Hamada, H. Breakthroughs and future challenges in left-right patterning. Dev. Growth Differ. Suppl. 2008, 1, S71-S78.

43. Collignon, J.; Varlet, I.; Robertson, E.J. Relationship between asymmetric nodal expression and the direction of embryonic turning. Nature 1996, 381, 155-158.

44. Raya, A.; Kawakami, Y.; Rodríguez-Esteban, C.; Ibañes, M.; Rasskin-Gutman, D.; RodríguezLeón, J.; Büscher, D.; Feijó, J.A.; Izpisúa Belmonte, J.C. Notch activity acts as a sensor for extracellular calcium during vertebrate left-right determination. Nature 2004, 427, 121-128.

45. Gourronc, F.; Ahmad, N.; Nedza, N.; Eggleston, T.; Rebagliati, M. Nodal activity around Kupffer's vesicle depends on the T-box transcription factors Notail and Spadetail and on Notch signaling. Dev. Dyn. 2007, 236, 2131-2146.

46. Meyers, E.N.; Martin, G.R. Differences in left-right axis pathways in mouse and chick: Functions of FGF8 and SHH. Science 1999, 285, 403-406.

47. Albertson, R.C.; Yelick, P.C. Roles for fgf8 signaling in left-right patterning of the visceral organs and craniofacial skeleton. Dev. Biol. 2005, 283, 310-321.

48. Nakaya, M.A.; Biris, K.; Tsukiyama, T.; Jaime, S.; Rawls, J.A.; Yamaguchi, T.P. Wnt3a links left-right determination with segmentation and anteroposterior axis elongation. Development 2005, 132, 5425-5436.

49. Rodríguez-Esteban, C.; Capdevila, J.; Kawakami, Y.; Izpisúa Belmonte, J.C. Wnt signaling and PKA control Nodal expression and left-right determination in the chick embryo. Development 2001, 128, 3189-3195.

50. Afzelius, B.A. A human syndrome caused by immotile cilia. Science 1976, 193, 317-319.

51. Afzelius, B.A. The immotile-cilia syndrome: A microtubule-associated defect. CRC Crit. Rev. Biochem. 1985, 19, 63-87.

52. Supp, D.M.; Witte, D.P.; Potter, S.S.; Brueckner, M. Mutation of an axonemal dynein affects left-right asymmetry in inversus viscerum mice. Nature 1997, 389, 963-966.

53. Sulik, K.; Dehart, D.B.; Iangaki, T.; Carson, J.L.; Vrablic, T.; Gesteland, K.; Schoenwolf, G.C. Morphogenesis of the murine node and notochordal plate. Dev. Dyn. 1994, 201, 260-278.

54. Singh, G.; Supp, D.M.; Schreiner, C.; McNeish, J.; Merker, H.J.; Copeland, N.G.; Jenkins, N.A.; Potter, S.S.; Scott, W. Legless insertional mutation: Morphological, molecular, and genetic characterization. Genes Dev. 1991, 5, 2245-2255.

55. Schreiner, C.M.; Scott, W.J.; Supp, D.M.; Potter, S.S. Correlation of forelimb malformation asymmetries with visceral organ situs in the transgenic mouse insertional mutation, legless. Dev. Biol. 1993, 158, 560-562.

56. Lowe, L.A.; Supp, D.M.; Sampath, K.; Yokoyama, T.; Wright, C.V.; Potter, S.S.; Overbeek, P.; Kuehn, M.R. Conserved left-right asymmetry of nodal expression and alterations in murine situs inversus. Nature 1996, 381,158-161.

57. Nonaka, S.; Tanaka, Y.; Okada, Y.; Takeda, S.; Harada, A.; Kanai, Y.; Kido, M.; Hirokawa, N. Randomization of left-right asymmetry due to loss of nodal cilia generating leftward flow of extraembryonic fluid in mice lacking KIF3B motor protein. Cell 1998, 95, 829-837.

58. Nonaka, S.; Yoshiba, S.; Watanabe, D.; Ikeuchi, S.; Goto, T.; Marshall, W.F.; Hamada, H. De novo formation of left-right asymmetry by posterior tilt of nodal cilia. PLoS Biol. 2005, 3, e268. 
59. Nonaka, S.; Shiratori, H.; Saijoh, Y.; Hamada, H. Determination of left-right patterning of the mouse embryo by artificial nodal flow. Nature 2002, 418, 96-99.

60. Okada, Y.; Nonaka, S.; Tanaka, Y.; Saijoh, Y.; Hamada, H.; Hirokawa, N. Abnormal nodal flow precedes situs inversus in iv and inv mice. Mol. Cell 1999, 4, 459-468.

61. Tanaka, Y.; Okada, Y.; Hirokawa, N. FGF-induced vesicular release of Sonic hedgehog and retinoic acid in leftward nodal flow is critical for left-right determination. Nature 2005, 435, 172-177.

62. McGrath, J.; Somlo, S.; Makova, S.; Tian, X.; Brueckner, M. Two populations of node monocilia initiate left-right asymmetry in the mouse. Cell 2003, 114, 61-73.

63. Tabin, C.J.; Vogan, K.J. A two-cilia model for vertebrate left-right axis specification. Genes Dev. 2003, 17, 1-6.

64. Essner, J.J.; Amack, J.D.; Nyholm, M.K.; Harris, E.B.; Yost, H.J. Kupffer's vesicle is a ciliated organ of asymmetry in the zebrafish embryo that initiates left-right development of the brain, heart and gut. Development 2005, 132, 1247-1760.

65. Kramer-Zucker, A.G.; Olale, F.; Haycraft, C.J.; Yoder, B.K.; Schier, A.F.; Drummond, I.A. Cilia-driven fluid flow in the zebrafish pronephros, brain and Kupffer's vesicle is required for normal organogenesis. Development 2005, 132, 1907-1921.

66. Hojo, M.; Takashima, S.; Kobayashi, D.; Sumeragi, A.; Shimada, A.; Tsukahara, T.; Yokoi, H.; Narita, T.; Jindo, T.; Kage, T.; Kitagawa, T.; Kimura, T.; Sekimizu, K.; Miyake, A.; Setiamarga, D.; Murakami, R.; Tsuda, S.; Ooki, S.; Kakihara, K.; Naruse, K.; Takeda, H. Right-elevated expression of charon is regulated by fluid flow in medaka Kupffer's vesicle. Dev. Growth Differ. 2007, 49, 395-405.

67. Neugebauer, J.M.; Amack, J.D.; Peterson, A.G.; Bisgrove, B.W.; Yost, H.J. FGF signalling during embryo development regulates cilia length in diverse epithelia. Nature 2009, 458, 651-654.

68. Okada, Y.; Takeda, S.; Tanaka, Y.; Belmonte, J.C.; Hirokawa, N. Mechanism of nodal flow: A conserved symmetry breaking event in left-right axis determination. Cell 2005, 121, 633-644.

69. Schweickert, A.; Weber, T.; Beyer, T.; Vick, P.; Bogusch, S.; Feistel, K.; Blum, M. Cilia-driven leftward flow determines laterality in Xenopus. Curr. Biol. 2007, 17, 60-66.

70. Vick, P.; Schweickert, A.; Weber, T.; Eberhardt, M.; Mencl, S.; Shcherbakov, D.; Beyer, T.; Blum, M. Flow on the right side of the gastrocoel roof plate is dispensable for symmetry breakage in the frog Xenopus laevis. Dev. Biol. 2009, 331, 281-291.

71. Essner, J.J.; Vogan, K.J.; Wagner, M.K.; Tabin, C.J.; Yost, H.J.; Brueckner, M. Conserved function for embryonic nodal cilia. Nature 2002, 418, 37-38.

72. Männer, J. Does an equivalent of the "ventral node" exist in chick embryos? A scanning electron microscopic study. Anat. Embryol. (Berl) 2001, 203, 481-490.

73. Pagán-Westphal, S.M.; Tabin, C.J. The transfer of left-right positional information during chick embryogenesis. Cell 1998, 93, 25-35.

74. Gros, J.; Feistel, K.; Viebahn, C.; Blum, M.; Tabin, C.J. Cell movements at Hensen's node establish left/right asymmetric gene expression in the chick. Science 2009, 324, 941-944.

75. Cui, C.; Little, C.D.; Rongish, B.J. Rotation of organizer tissue contributes to left-right asymmetry. Anat. Rec. (Hoboken) 2009, 292, 557-561. 
76. Levin, M.; Thorlin, T.; Robinson, K.R.; Nogi, T.; Mercola, M. Asymmetries in H+/K+-ATPase and cell membrane potentials comprise a very early step in left-right patterning. Cell 2002, 111, 77-89.

77. Levin, M.; Mercola, M. Gap junctions are involved in the early generation of left-right asymmetry. Dev. Biol. 1998, 203, 90-105.

78. Levin, M.; Mercola, M. Gap junction-mediated transfer of left-right patterning signals in the early chick blastoderm is upstream of Shh asymmetry in the node. Development 1999, 126, 4703-4714.

79. Kawakami, Y.; Raya, A.; Raya, R.M.; Rodríguez-Esteban, C.; Belmonte, J.C. Retinoic acid signalling links left-right asymmetric patterning and bilaterally symmetric somitogenesis in the zebrafish embryo. Nature 2005, 435, 165-171.

80. Adams, D.S.; Robinson, K.R.; Fukumoto, T.; Yuan, S.; Albertson, R.C.; Yelick, P.; Kuo, L.; McSweeney, M.; Levin, M. Early, H+-V-ATPase-dependent proton flux is necessary for consistent left-right patterning of non-mammalian vertebrates. Development 2006, 133, 1657-1671.

81. Shu, X.; Huang, J.; Dong, Y.; Choi, J.; Langenbacher, A.; Chen, J.N. Na,K-ATPase alpha2 and Ncx4a regulate zebrafish left-right patterning. Development 2007, 134, 1921-1930.

82. Sarmah, B.; Latimer, A.J.; Appel, B.; Wente, S.R. Inositol polyphosphates regulate zebrafish left-right asymmetry. Dev. Cell 2005, 9, 133-145.

83. Hatler, J.M.; Essner, J.J.; Johnson, R.G. A gap junction connexin is required in the vertebrate left-right organizer. Dev. Biol. 2009, 336, 183-191.

84. Fukumoto, T.; Kema, I.P.; Levin, M. Serotonin signaling is a very early step in patterning of the left-right axis in chick and frog embryos. Curr. Biol. 2005, 15, 794-803.

85. Fukumoto, T.; Blakely, R.; Levin, M. Serotonin transporter function is an early step in left-right patterning in chick and frog embryos. Dev. Neurosci. 2005, 27, 349-363.

86. Gardner, R.L. Normal bias in the direction of fetal rotation depends on blastomere composition during early cleavage in the mouse. PLoS One 2010, 5, e9610.

87. Kuroda, R.; Endo, B.; Abe, M.; Shimizu, M. Chiral blastomere arrangement dictates zygotic left-right asymmetry pathway in snails. Nature 2009, 462, 790-794.

88. Brend, T.; Holley, S.A. Balancing segmentation and laterality during vertebrate development. Semin. Cell Dev. Biol. 2009, 20, 472-478.

89. Niederreither, K.; Dollé, P. Retinoic acid in development: Towards an integrated view. Nat. Rev. Genet. 2008, 9, 541-553.

90. Vermot, J.; Gallego Llamas, J.; Fraulob, V.; Niederreither, K.; Chambon, P.; Dollé, P. Retinoic acid controls the bilateral symmetry of somite formation in the mouse embryo. Science 2005, 308, 563-566.

91. Lowe, L.A.; Supp, D.M.; Sampath, K.; Yokoyama, T.; Wright, C.V.; Potter, S.S.; Overbeek, P.; Kuehn, M.R. Conserved left-right asymmetry of nodal expression and alterations in murine situs inversus. Nature 1996, 381, 158-161.

92. Long, S.; Ahmad, N.; Rebagliati, M. The zebrafish nodal-related gene southpaw is required for visceral and diencephalic left-right asymmetry. Development 2003, 130, 2303-2316.

93. Sirbu, I.O.; Duester, G. Retinoic-acid signalling in node ectoderm and posterior neural plate directs left-right patterning of somitic mesoderm. Nat. Cell Biol. 2006, 8, 271-277. 
94. Vermot, J.; Pourquié, O. Retinoic acid coordinates somitogenesis and left-right patterning in vertebrate embryos. Nature 2005, 435, 215-220.

95. Vilhais-Neto, G.C.; Maruhashi, M.; Smith, K.T.; Vasseur-Cognet, M.; Peterson, A.S.; Workman, J.L.; Pourquié, O. Rere controls retinoic acid signalling and somite bilateral symmetry. Nature 2010, 463, 953-957.

96. Boettger, T.; Wittler, L.; Kessel, M. FGF8 functions in the specification of the right body side of the chick. Curr. Biol. 1999, 9, 277-280.

97. Isaac, A.; Sargent, M.G.; Cooke, J. Control of vertebrate left-right asymmetry by a snail-related zinc finger gene. Science 1997, 275, 1301-1304.

98. Sefton, M.; Sánchez, S.; Nieto, M.A. Conserved and divergent roles for members of the Snail family of transcription factors in the chick and mouse embryo. Development 1998, 125, 3111-3121.

99. Morales, A.V.; Acloque, H.; Ocaña, O.H.; de Frutos, C.A.; Gold, V.; Nieto, M.A. Snail genes at the crossroads of symmetric and asymmetric processes in the developing mesoderm. EMBO Rep. 2007, 8, 104-109.

100. Fior, R.; Henrique, D. "Notch-Off": A perspective on the termination of Notch signalling. Int. J. Dev. Biol. 2009, 53, 1379-1384.

101. Echeverri, K.; Oates, A.C. Coordination of symmetric cyclic gene expression during somitogenesis by Suppressor of Hairless involves regulation of retinoic acid catabolism. Dev. Biol. 2007, 301, 388-403.

102. Saúde, L.; Lourenço, R.; Gonçalves, A.; Palmeirim, I. Terra is a left-right asymmetry gene required for left-right synchronization of the segmentation clock. Nat. Cell Biol. 2005, 7, 918-920.

103. Seo, K.W.; Wang, Y.; Kokubo, H.; Kettlewell, J.R.; Zarkower, D.A.; Johnson, R.L. Targeted disruption of the DM domain containing transcription factor Dmrt2 reveals an essential role in somite patterning. Dev. Biol. 2006, 290, 200-210.

104. Andrade R.P.; Palmeirim, I; Bajanca, F. Molecular clocks underlying vertebrate embryo segmentation: A 10-year-old hairy-go-round. Birth Defects Res. C Embryo Today 2007, 81, 65-83.

105. Bulman, M.P.; Kusumi, K.; Frayling, T.M.; McKeown, C.; Garrett, C.; Lander, E.S.; Krumlauf, R.; Hattersley, A.T.; Ellard, S.; Turnpenny, P.D. Mutations in the human delta homologue, DLL3, cause axial skeletal defects in spondylocostal dysostosis. Nat. Genet. 2000, 24, 438-441.

106. Whittock, N.V.; Sparrow, D.B.; Wouters, M.A.; Sillence, D.; Ellard, S.; Dunwoodie, S.L.; Turnpenny, P.D. Mutated MESP2 causes spondylocostal dysostosis in humans. Am. J. Hum. Genet. 2004, 74, 1249-1254.

107. Sparrow, D.B.; Chapman, G.; Wouters, M.A.; Whittock, N.V.; Ellard, S.; Fatkin, D.; Turnpenny, P.D.; Kusumi, K.; Sillence, D.; Dunwoodie, S.L. Mutation of the LUNATIC FRINGE gene in humans causes spondylocostal dysostosis with a severe vertebral phenotype. Am. J. Hum. Genet. 2006, 78, 28-37.

108. Gruneberg, H. Genetical studies on the skeleton of the mouse: XXIX. PUDGY. Genet. Res. 1961, 2, 384-393.

109. Saga, Y.; Hata, N.; Koseki, H.; Taketo, M.M. Mesp2: A novel mouse gene expressed in the presegmented mesoderm and essential for segmentation initiation. Genes Dev. 1997, 11, 1827-1839.

110. Zhang, N.; Gridley, T. Defects in somite formation in lunatic fringe-deficient mice. Nature 1998, 394, 374-377. 
111. McDaniell, R.; Warthen, D.M.; Sanchez-Lara, P.A.; Pai, A.; Krantz, I.D.; Piccoli, D.A.; Spinner, N.B. NOTCH2 mutations cause Alagille syndrome, a heterogeneous disorder of the notch signaling pathway. Am. J. Hum. Genet. 2006, 79, 169-173.

112. Kreiborg, S.; Barr, M.J.; Cohen, M.M.J. Cervical spine in the Apert syndrome. Am. J. Med. Genet. 1992, 43, 704-708.

113. Ramsdell, A.F. Left-right asymmetry and congenital cardiac defects: getting to the heart of the matter in vertebrate left-right axis determination. Dev. Biol. 2005, 288, 1-20.

114. Lurie, I.W.; Kappetein, A.P.; Loffredo, C.A.; Ferencz, C. Non-cardiac malformations in individuals with outflow tract defects of the heart: The Baltimore-Washington Infant Study (1981-1989). Am. J. Med. Genet. 1995, 59, 76-84.

115. Nugent, E.W.; Plauth, W.H.; Edwards, J.E. The Pathology, Pathophysiology, Recognition and Treatment of Congenital Heart Disease; McGraw-Hill: New York, NY, USA, 1994.

116. Sternick, E.B.; Márcio Gerken, L.; Max, R.; Osvaldo Vrandecic, M. Radiofrequency catheter ablation of an accessory pathway in a patient with Wolff-Parkinson-White and Kartagener's syndrome. Pacing Clin. Electrophysiol. 2004, 27, 401-404.

117. Bowers, P.N.; Brueckner, M.; Yost, H.J. The genetics of left-right development and heterotaxia. Semin. Perinatol. 1996, 20, 577-588.

118. Kartagener, M.; Stucki, P. Bronchiectasis with situs inversus. Arch. Pediatr. 1962, 79, 193-207.

119. Kennedy, M.P.; Omran, H.; Leigh, M.W.; Dell, S.; Morgan, L.; Molina, P.L.; Robinson, B.V.; Minnix, S.L.; Olbrich, H.; Severin, T.; Ahrens, P.; Lange, L.; Morillas, H.N.; Noone, P.G.; Zariwala, M.A.; Knowles, M.R. Congenital heart disease and other heterotaxic defects in a large cohort of patients with primary ciliary dyskinesia. Circulation 2007. 115, 2814-2821.

120. Debrus, S.; Sauer, U.; Gilgenkrantz, S.; Jost, W.; Jesberger, H.J.; Bouvagnet, P. Autosomal recessive lateralization and midline defects: Blastogenesis recessive 1. Am. J. Med. Genet. 1997, 68, 401-404.

121. Levin, M. Left-right asymmetry in embryonic development: A comprehensive review. Mech. Dev. 2005, 122, 3-25.

(C) 2010 by the authors; licensee MDPI, Basel, Switzerland. This article is an Open Access article distributed under the terms and conditions of the Creative Commons Attribution license (http://creativecommons.org/licenses/by/3.0/). 